\title{
Estimation of Unobserved Inflation Expectations in India Using State-Space Model
}

\author{
Siddhartha Chattopadhyay ${ }^{1}$, Sohini Sahu², Saakshi² \\ ${ }^{1}$ Department of Humanities and Social Sciences, Indian Institute of Technology, Kharagpur, India \\ ${ }^{2}$ Department of Economic Sciences, Indian Institute of Technology, Kanpur, India \\ Email: *siddhartha@hss.iitkgp.ernet.in, ssahu@iitk.ac.in, saaki@iitk. ac.in
}

How to cite this paper: Chattopadhyay, S., Sahu, S. and Saakshi (2019) Estimation of Unobserved Inflation Expectations in India Using State-Space Model. Theoretical Economics Letters, 9, 1480-1488. https://doi.org/10.4236/tel.2019.95095

Received: January 25, 2019

Accepted: June 16, 2019

Published: June 19, 2019

Copyright (c) 2019 by author(s) and Scientific Research Publishing Inc. This work is licensed under the Creative Commons Attribution International License (CC BY 4.0).

http://creativecommons.org/licenses/by/4.0/

\begin{abstract}
This paper estimates the unobserved inflation expectations in India between 1993: Q1 to 2017: Q1 from the Fisher equation relation based on the state space approach using Kalman Filter. We find inflation forecast obtained from Fischer equation by applying Kalman Filter match well with the inflation forecasts made by the Survey of Professional Forecasters and Inflation Expectations Survey of Household conducted by the Reserve Bank of India and the International Monetary Fund for the Indian economy.
\end{abstract}

\section{Keywords}

Fisher Equation, Kalman Filter, Expected Inflation, India

\section{Introduction}

Inflation expectation is an important marker for monetary policy makers. Both theoretically and empirically, it has been established that current inflation is influenced by expectations about future inflation and vice-versa. Especially for economies where inflation targeting is an explicit policy goal, knowledge of inflation expectations is required to attain inflation anchoring. Recently RBI has undertaken inflation targeting as one of the major monetary policy objectives for India. However, data of inflation expectation given by RBI in Inflation Expectation Survey of Household (IESH) and Survey of Professional Forecasters (SPF) are very limited. RBI started publishing quarterly IESH from third quarter of 2006 and SPF from fourth quarter of 2007. Hence, obtaining alternative measure of inflation forecast for a reasonably longer time period is required. This paper calculates the inflation forecast of India by applying unobserved component modelling based on Kalman Filter (KF) to the Fisher equation.

The inflation dynamics, as captured by the New Keynesian Phillips Curve 
(NKPC), has inflation expectations as one of its explanatory variables. In this context, various authors have used different specifications of inflation expectations, a comprehensive survey of which can be found in Mavroeidis et al. ${ }^{1}$ [1]

In the Indian context, authors have modelled the unobserved inflation expectations following techniques like perfect foresight [3] [4] [5] [6], moving average [7], single and double exponential smoothing [7] etc. Our work adds to the existing literature by using another procedure for estimating expected inflation of India.

This paper estimates the unobserved inflation expectations in India based on the Fisher equation relation using the state space approach or the KF method following Mishkin [8], Fama and Gibbons [9], Burmeister et al. [10] and Hamilton [11]. The novelty of this methodology when compared to the other techniques is that expected inflation is estimated from a well-established economic relationship which is the Fisher equation. Looking at it from another perspective, this estimation also verifies if the Fisher equation holds for the Indian economy. We find that between 1993: Q1 and 2017: Q1 the unobserved inflation expectations estimated from the Fisher equation match well with inflation forecasts made by the Survey of Professional Forecasters and Inflation Expectation Survey of Household conducted by the Reserve Bank of India (RBI) and the forecasts by the International Monetary Fund (IMF) for the Indian economy.

Given that the survey-based inflation expectations data for India are relatively recent and hence the data points are limited, our methodology ensures that the expected inflation estimated from the Fisher Equation can go back in time, even before the availability of survey-based inflation expectations data.

The paper proceeds as follows. We present the methodology in Section 2, followed by the data description in Section 3. Section 4 concludes the paper.

\section{Methodology}

Our starting point is the Fisher equation that relates the nominal interest rate and the real interest rate. It is given by the following equation:

$$
r r_{t}^{a}=i_{t}-\pi_{t}^{e}
$$

where, $r r_{t}^{a}$ is the ex-ante real interest rate, $i_{t}$ is the nominal interest rate captured by the policy rate and $\pi_{t}^{e}=E_{t}\left(\pi_{t+1}\right)$ is the expected inflation rate. Note that ex-ante real interest rate is unobserved since the expected inflation is unobserved. The ex-post real interest rate is $r r_{t}=i_{t}-\pi_{t}$.

Our variable of interest here is the one period ahead expected inflation. We apply the state space approach based on KF to the Fisher equation to estimate inflation expectation ${ }^{2}$. To do so, we decompose ex-post real interest rate $r r_{t}$, into ex-ante real interest rate, $r r_{t}^{a}$ and the forecast error, $\mu_{t}=\pi_{t}^{e}-\pi_{t}$ as shown in Equation (2). We further assume that ex-ante real interest rate follows

${ }^{1} \mathrm{~A}$ more general treatment of modelling unobserved components in structural time series models can be found in Harvey [2].

${ }^{2}$ See Appendix for a brief outline of Kalman Filter methodology. 
an $\mathrm{AR}(1)$ process as given in Equation (3) ${ }^{3}$.

$$
\begin{gathered}
r r_{t}=r r_{t}^{a}+\mu_{t} \\
r r_{t}^{a}=\rho r r_{t-1}^{a}+\varepsilon_{t}
\end{gathered}
$$

where, $\rho \in(0,1)$ is the persistence. We assume, $\mu_{t} \sim \operatorname{IN}(0,1)$ and $\varepsilon_{t} \sim \operatorname{IN}(0,1)$ and independent of each other for all $t$.

Note, Equation (2) is our signal equation and Equation (3) is our state equation. We apply KF on Equation (2) and Equation (3) and estimate the parameters numerically through MLE using following initial conditions,

$\rho=0.83, \pi_{0}^{f}=8, \sigma_{u}^{2}=1.87$ for our estimation ${ }^{4}$. These initial conditions yield $r r_{10}=4$. However, we do not have any prior information about the variance of the state variable, ex-ante real interest rate. Hence, we have used diffuse prior for obtaining an initial guess of the variance of state variable, $P_{100}{ }^{5}$. Once convergence is achieved after 7 iterations, expected inflation is calculated as, $\hat{\pi}_{t}^{e}=i_{t}-\hat{\pi}_{t \mid t-1}^{a}$.

\section{Data}

Quarterly data on CPI for India between 1992: Q1 to 2017: Q1 has been collected from the FRED database provided by the Federal Reserve Bank of St. Louis. For quarterly nominal interest rate for India, we have used 91 days Treasury bill rate collected from different volumes of RBI bulletin. Inflation forecasts made by the International Monetary Fund are collected from World Economic Outlook Database $^{6}$. The data on Survey of Professional Forecasters (SPF) and Inflation Expectations Survey of Households (IESH) are collected from different issues of RBI bulletin. We have used data of inflation rate based on WPI and CPI and 91 days Treasury bill rate to calculate expected inflation from Fisher equation by applying KF. There is no missing date in either of these series.

\section{Results}

Figure 1 plots the one period ahead expected quarterly inflation for India between 1993: Q2 and 2017: Q1 generated by applying the KF to the Fisher equation along with the actual inflation based on WPI. Actual inflation and its forecast are measured in percentage. Figure 2 on the other hand plots the inflation forecast of SPF with the same based on CPI after applying KF. Both figures show that inflation forecast obtained by using KF to Fisher equation do a very good job.

\footnotetext{
${ }^{3}$ We have checked that ex-post real interest rate is AR(1). See Appendix for detail.

${ }^{4} \mathrm{~A}$ simple correlogram shows that, ex-post real interest rate is a process with first autocorrelation coefficient 0.89 and variance, 1.89. As a result, initial value of $\rho=0.89$. We have decomposed the inflation rate into trend and cycle through HP filter. We set, $\pi_{10}=8$ which is the inflation rate for 1992: 4. Appendix shows the plot of inflation and its trend obtained from HP filter. We have achieved convergence after 7 iterations. See Appendix for the correlogram and descriptive statistics of ex-post real interest rate.

${ }^{5}$ For details see, Harvey [12] and Koopman, Shephard and Doornik [13].

${ }^{6} \mathrm{IMF}$ publishes biannual inflation forecast for Fall and Spring from 1990 onwards. It publishes inflation forecast for one year and two year ahead. We have used only one year ahead forecast in our paper.
} 


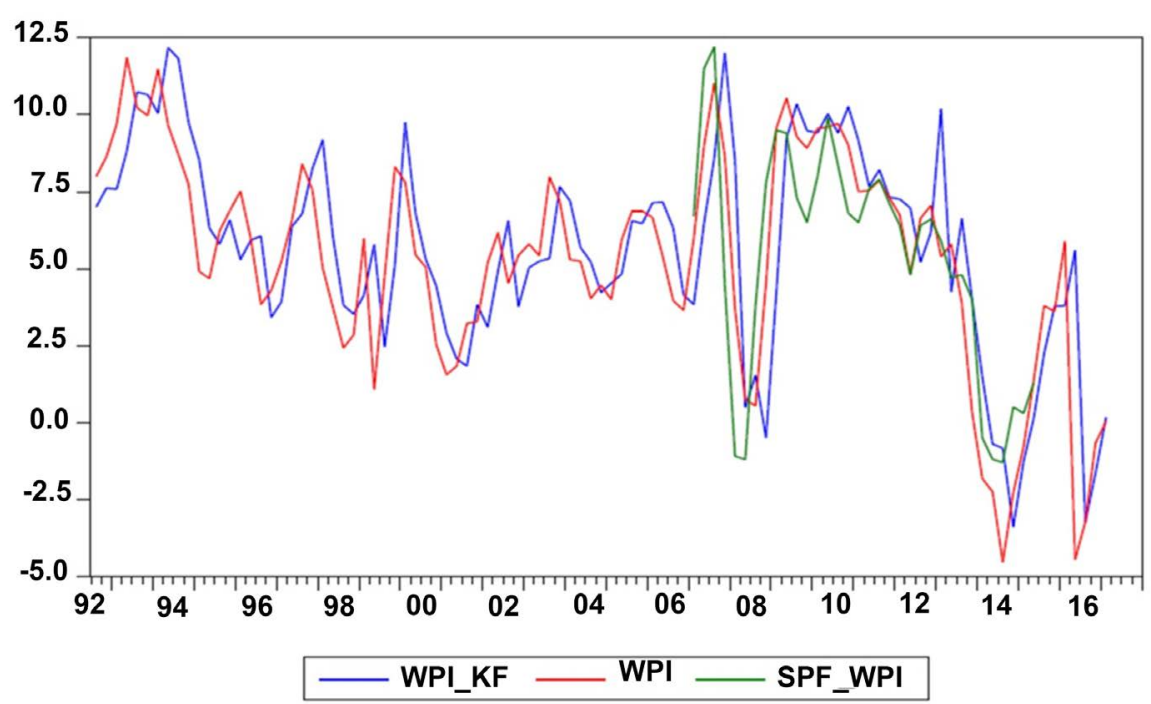

Figure 1. Inflation based on WPI and its forecast.

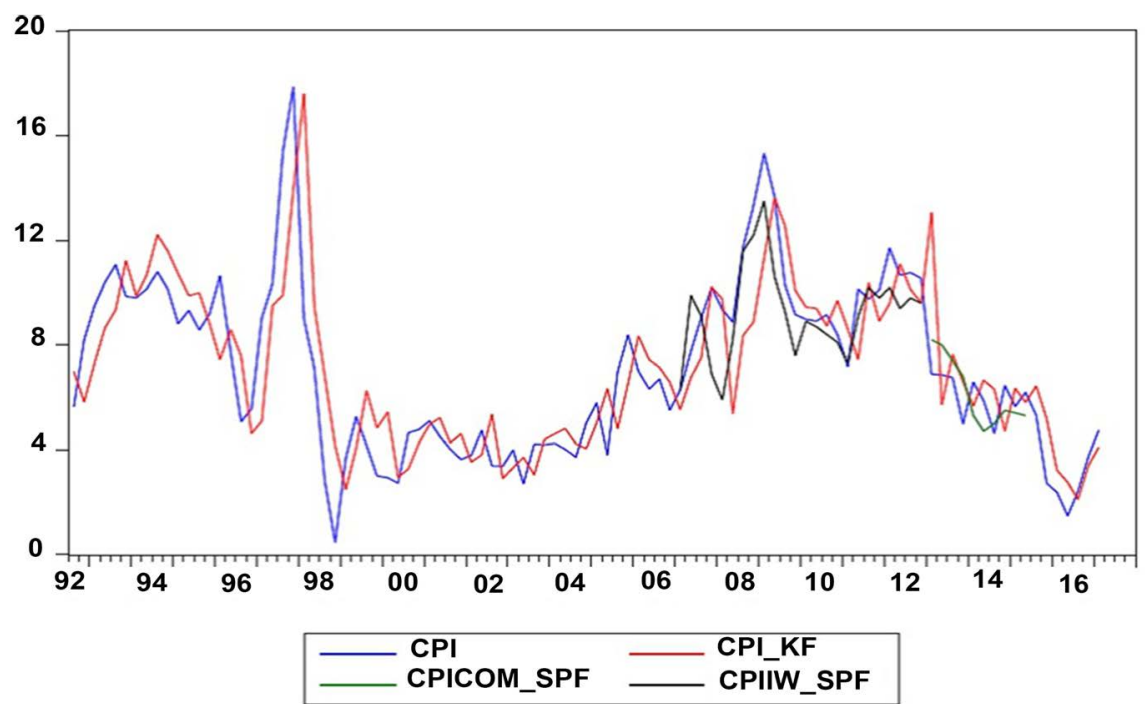

Figure 2. Inflation based on CPI and its forecast.

Note, initial forecast obtained from KF is sensitive to initial guess but it quickly converges to SPF inflation forecast of IMF as shown in Figure 2. Figure 2 shows that, forecast of KF quickly converges to IMF forecast from 1994: Q1 when the estimation starts from 1993: Q1.

Figure 3 and Figure 4 compare the inflation forecast from KF with the same given by IMF and IESH of RBI. Both figures also show evidence in favour of Fisher equation holding for India as the inflation forecast obtained from it through KF matches the data quite well.

Table 1 gives us the descriptive statistics of inflation based on WPI and CPI along with their forecast based on KF, as well as the inflation forecasts made by the IMF for the Indian economy. Results indicate that mean, median and variance of forecast are very close to our actual inflation. 


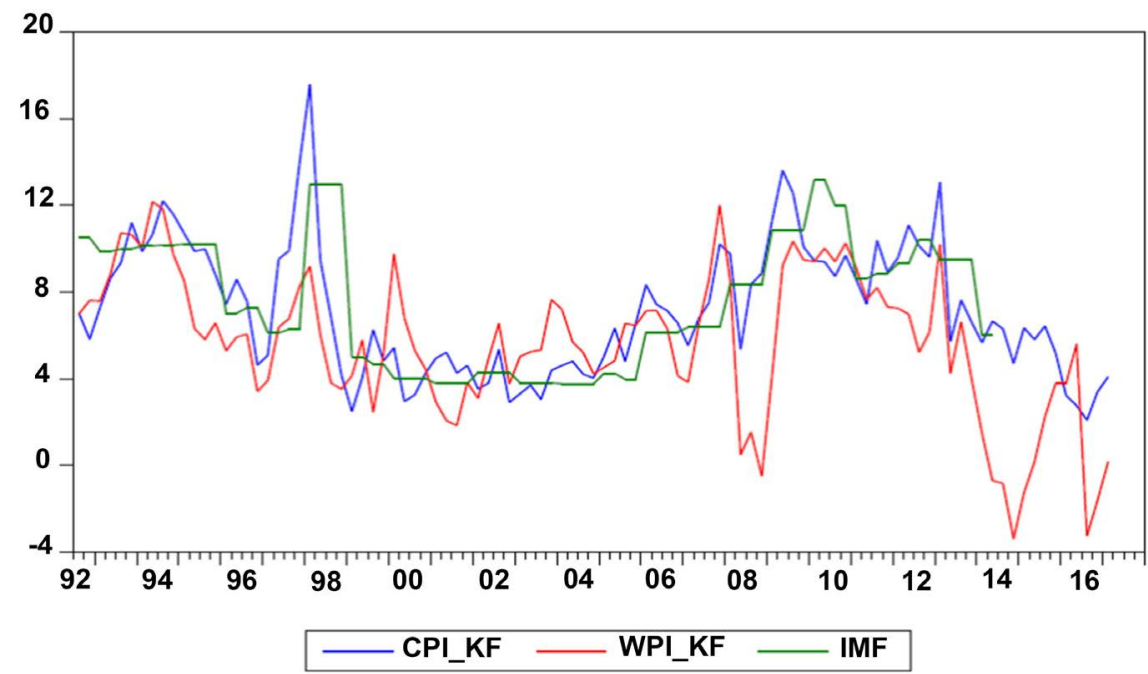

Figure 3. Inflation forecasts of IMF and Kalman filter.

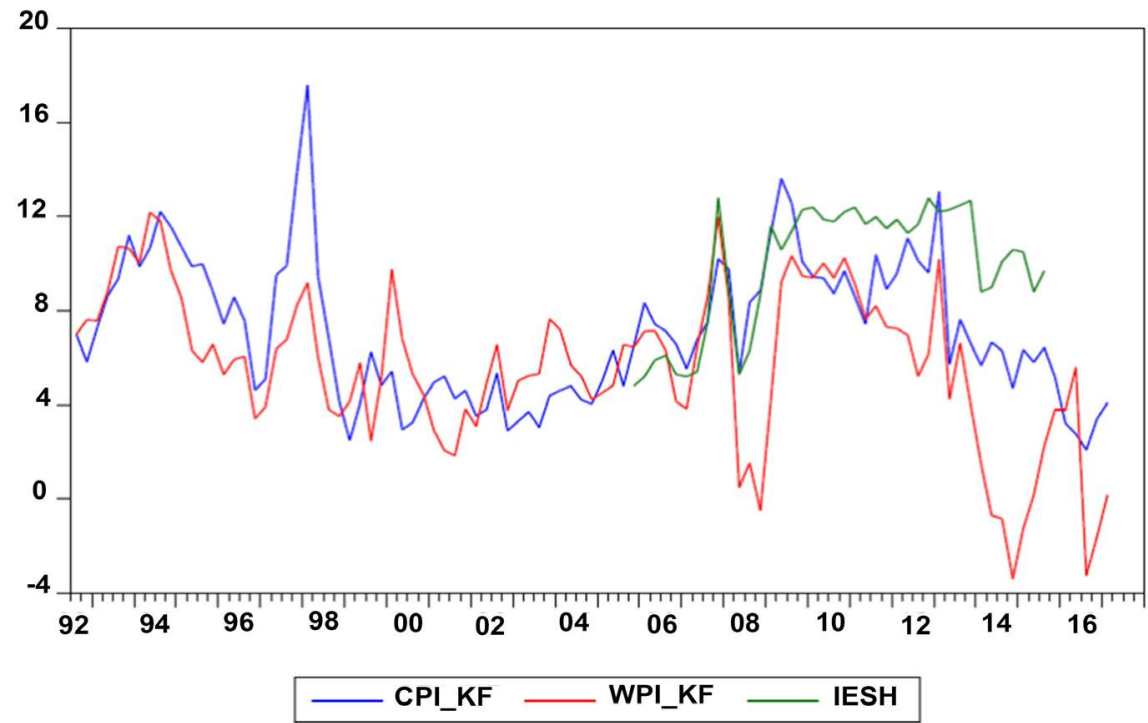

Figure 4. Inflation Forecasts of IESH and Kalman Filter.

Table 1. Descriptive statistics.

\begin{tabular}{cccccc}
\hline & CPI & WPI & IMF Forecast & CPI_KF & WPI_KF \\
\hline Mean & 7.10 & 5.34 & 7.58 & 7.16 & 5.65 \\
Median & 6.76 & 5.44 & 7.25 & 6.65 & 5.92 \\
Maximum & 17.86 & 11.86 & 13.18 & 17.59 & 12.17 \\
Minimum & 0.46 & -4.55 & 3.76 & 2.08 & -3.40 \\
Standard Deviation & 3.32 & 3.50 & 2.95 & 3.02 & 3.34 \\
\hline
\end{tabular}

\section{Conclusions}

This paper estimates the unobserved quarterly inflation expectations in India between 1993: Q1 and 2017: Q1 from the Fisher equation by using the state-space 
model. Our estimates match well with the inflation forecasts made by the SPF and IESH conducted by the RBI and the inflation forecasts of India made by the IMF. Our analysis also shows that Fisher equation does hold for India as the inflation forecast obtained from it by applying KF matches the data quite well.

Recently India has undertaken inflation targeting as one of the major monetary policy objectives. Achieving this objective requires information about inflation forecast to anchor inflationary expectations. However, data of inflation expectation given by RBI in IESH and SPF are very limited. RBI started publishing quarterly IESH from third quarter of 2006 and SPF from fourth quarter of 2007. Hence, obtaining alternative measure of inflation forecast for a reasonably longer time period is required. The uniqueness of our paper is that, it provides an alternative methodology to estimate inflation expectations of India for a reasonable longer period of time. Our methodology uses Fisher equation to estimate inflation forecast of India and hence has a strong theoretical foundation. Note, the inflation expectation obtained using our methodology nicely matches the survey data published by RBI. Moreover, long time series of monthly inflation and 91-days treasury bill rate are available for India. Therefore, our methodology of forecasting inflation expectations by KF can be used to get a longer time series of inflation expectations for India. Hence, data of inflation expectations obtained by our methodology are expected to facilitate the research on inflation forecast and monetary policy of India significantly.

\section{Acknowledgements}

We express our gratitude to Kajal Lahiri Distinguished Professor of Economics, SUNY-Albany for helpful discussion.

\section{Conflicts of Interest}

The authors declare no conflicts of interest regarding the publication of this paper.

\section{References}

[1] Mavroeidis, S., Plagborg-Møller, M. and Stock, J.H. (2014) Empirical Evidence on Inflation Expectations in the New Keynesian Phillips Curve. Journal of Economic Literature, 52, 124-188. https://doi.org/10.1257/jel.52.1.124

[2] Harvey, A. (2006) Forecasting with Unobserved Components Time Series Models. In: Handbook of Economic Forecasting, Elsevier, Amsterdam, Vol. 1, 327-412. https://doi.org/10.1016/S1574-0706(05)01007-4

[3] Srinivasan, N., Mahambare, V. and Ramachandran, M. (2006) Modelling Inflation in India: A Critique of the Structuralist Approach. Journal of Quantitive Economics, 4, 45-58.

[4] Patra, M.D. and Kapur, M. (2010) A Monetary Policy Model without Money for India. IMF Working Paper Series, WP/10/183. https://doi.org/10.5089/9781455202171.001

[5] Sahu, J.P. (2013) Inflation Dynamics in India: A Hybrid New Keynesian Phillips 
Curve Approach. Economics Bulletin, 33, 2634-2647.

[6] Patra, M.D. and Ray, P. (2010) Inflation Expectations and Monetary Policy in India: An Empirical Exploration. IMF Working Paper Series, WP/10/84. https://doi.org/10.5089/9781451982640.001

[7] Dua, P. and Gaur, U. (2010) Determination of Inflation in an Open Economy Phillips Curve Framework: The Case of Developed and Developing Asian Countries. Macroeconomics and Finance in Emerging Market Economies, 3, 33-51. https://doi.org/10.1080/17520840903498107

[8] Mishkin, F.S. (1981) The Real Rate of Interest: An Empirical Investigation. Carnegie-Rochester Conference Series on Public Policy, No. 15, 151-200. https://doi.org/10.1016/0167-2231(81)90022-1

[9] Fama, E.F. and Gibbons, M.R. (1982) Inflation, Real Returns and Capital Investment. Journal of Monetary Economics, 9, 297-323. https://doi.org/10.1016/0304-3932(82)90021-6

[10] Edwin, B., Wall, K.D. and Hamilton, J.D. (1986) Estimation of Unobserved Expected Monthly Inflation Using KalmanFilterng. Journal of Business \& Economic Statistics, 4, 147-160. https://doi.org/10.1080/07350015.1986.10509510

[11] Hamilto, J.D. (1994) Time Series Analysis. Princeton University Press, Princeton.

[12] Harvey, A. (1989) Forecasting Structural Time Series Models and the KalmanFolter. Cambridge University Press, Cambridge.

[13] Jan, K.S., Shephard, N. and Doornik, J.A. (1999) Statistical Algorithms for Models in State Space Using SsfPack 2.2. Econometrics Journal, 2, 113-166. https://doi.org/10.1111/1368-423X.00023 


\section{Appendix}

\section{The Kalman Filter}

$\mathrm{KF}$ is an Unobserved Component Modelling (UCM) which extracts an unobserved state recursively form an observed signal equation. To explain KF assume a signal equation,

$$
y_{t}=A+B s_{t}+\mu_{t}
$$

Here, the observed signal is $y_{t}:(N \times 1)$, unobserved state variable is $s_{t}:(K \times 1)$, the coefficient matrix $A:(N \times 1)$, represents intercept and $B:(N \times K) . \mu_{t}:(N \times 1)$ is random error. We assume, $\mu_{t} \sim N\left(0, \sum_{\mu}\right)$, where $\sum_{\mu}:(N \times N)$.

We assume the state equation is,

$$
s_{t}=\Phi S_{t-1}+v_{t}
$$

Here, $\Phi:(K \times K)$ and $\mu_{t} \sim N\left(0, \sum_{v}\right)$, where $\sum_{v}:(K \times K)$. The random error term is signal $(\mu)$ and state $(v)$ are assumed to be independent of each other.

The objective of KF is to estimate the unobserved state variable $s_{t}$. The unobserved state variable is estimated recursively from equation (ref: prediction) to (ref: update) as given below.

$$
\begin{gathered}
s_{t \mid t-1}=\Phi s_{t-1 \mid t-1} \\
P_{t \mid t-1}=\Phi P_{t-1 \mid t-1} \Phi^{\prime}+\sum_{v} \\
y_{t \mid t-1}=A+B s_{t \mid t-1} \\
V_{t \mid t-1}=B P_{t \mid t-1} B^{\prime}+\sum_{v}
\end{gathered}
$$

(Prediction)

(Observation)

and,

$$
\begin{gathered}
s_{t \mid t}=s_{t \mid t-1}+P_{t \mid t-1}+B^{\prime} V_{t \mid t-1}^{-1}\left(y_{t}-y_{t-1}\right) \\
P_{t \mid t}=P_{t \mid t-1}+P_{t \mid t-1}+B^{\prime} V_{t \mid t-1}^{-1} B P_{t \mid t-1}
\end{gathered}
$$

Here, the $y_{t \mid t-1}=E_{t-1}\left(y_{t}\right)$ is the conditional mean of $y_{t}$ given the information available till $(t-1)$. The conditional variance of $y_{t}$ is $V_{t \mid t-1}$. The best estimator of state is, $s_{t \mid t-1}=E_{t-1}\left(s_{t}\right)$ with variance $P_{t \mid t-1}$. Here, the Kalman gain is,

$$
K_{t}=P_{t \mid t-1} B^{\prime} V_{t \mid t-1}^{-1}
$$

The Kalman gain is determined as a factor that minimizes the variance of state update $s_{t \mid t}$. The variance of state update is, $P_{t \mid t}$.

The parameter of the model is $\Theta=\left(A, B, \Phi, \sum_{\mu}, \Sigma_{v}\right)$. Note,

$$
y_{t} \sim N\left(y_{t \mid t-1}, V_{t \mid t-1}\right)
$$

Here, $y_{t \mid t-1}$ and $V_{t \mid t-1}$ and non-linear functions of $\Theta$. As a result $\Theta$ is estimated numerically by Maximum Likelihood Estimation as follows,

$$
\underset{\Theta}{\operatorname{minimize}} l=\frac{1}{T} \sum_{t=1}^{T} l_{t}
$$




$$
l_{t}=-\frac{N}{2} \log (2 \pi)-\frac{1}{2} \log \left(V_{t \mid t-1}\right)-\frac{1}{2}\left(y_{t}-y_{t-1}\right)^{\prime} V_{t \mid t-1}^{-1}\left(y_{t}-y_{t-1}\right)
$$

given the initial condition, $s_{1 \mid 0}, P_{1 \mid 0}$ and $\Theta_{0}$. We can accordingly draw statistical inferences from,

$$
\hat{\Theta}_{M L E} \sim A N\left[\Theta,\left(I(\Theta)_{\Theta=\hat{\Theta}_{M L E}}\right)^{-1}\right]
$$

where, $I(\Theta)$ is the Fisher Information Matrix. 